\title{
Hydrophobisation of clays and nano silica for ground engineering
}

\author{
Yunesh Saulick ${ }^{1, *}$ and Sergio Lourenço ${ }^{1, * *}$ \\ ${ }^{1}$ Department of Civil Engineering, Haking Wong Building, The University of Hong Kong, Pokfulam Road, Hong Kong, China
}

\begin{abstract}
Altering the hydrophobicity of particles allows their use as functional construction materials in ground engineering (e.g. in barriers). This study examines the hydrophobisation of nano to micro particles by using two clays (kaolin and halloysite) and nano silica. To induce hydrophobicity, dimethyldichlorosilane (DMDCS) was used in concentrations varying from $0.25 \%$ to $20 \%$. The sessile drop method was used to measure the contact angle (CA) of the particles. Kaolin was initially hydrophobic with a CA of $93 \pm 5^{\circ}$ while the other two materials were hydrophilic. The addition of DMDCS to the materials increased CAs of all materials investigated. The maximum CAs recorded at $20 \%$ for the halloysite, kaolin and nano silica were respectively: $116 \pm 5^{\circ}, 143 \pm 3^{\circ}$ and $144 \pm 6^{\circ}$. The difference in CAs attained by the clays was attributed to their different structure. Scanning electron microscope-energy dispersive spectroscopy analysis showed increases in carbon content with only halloysite and nano silica after hydrophobisation. The results demonstrate that hydrophobising clays and nano silica can effectively improve their resistance to water infiltration.
\end{abstract}

\section{Introduction}

In the construction industry, materials with functional properties are much coveted due to the continuous upgrades in worldwide standards, pivoting progressively towards climate-resilient infrastructures. Functionalising materials such as sands, silts and clays to render them hydrophobic can singularly lead to several applications in the construction industry e.g. as a final cover system in a landfill. The hydrophobicity of a material can be directly characterised by the contact angle (CA), the angle formed at the solid-liquid-vapour phase of the boundary when a drop of liquid is dispensed on it. The lower and upper bound limits of the $\mathrm{CA}$ are $0^{\circ}$ and $180^{\circ}$. Functional materials displaying hydrophobicity have CAs exceeding $90^{\circ}$ e.g. CAs of $124^{\circ}, 137^{\circ}$ and $134^{\circ}$ have been reported on hydrophobic sands, silts and clays respectively [1-3].

In nature, hydrophobicity in soil can occur as a result of organic matter coating the particles such as humic materials, fungal hyphae, waxes originating from vegetation, microbial activity and substances produced during plant decomposition [4-8]. However, these hydrophobic coatings may not be suited for construction purposes since they may be easily abraded, resulting in a heterogeneous distribution of hydrophobicity. Therefore, to obtain stable and homogeneous levels of hydrophobicity, synthesis is carried out using chemical agents such as organosilanes [1] e.g. dimethyldichlorosilane, fatty acids $[9,10]$ e.g. oleic acid and petroleum-based waxes [11]. While studies relating to the hydrophobisation of sands and silts to be used as innovative construction materials in ground engineering have been amply investigated, the effects of chemi-

\footnotetext{
*e-mail: yunesh@connect.hku.hk

**e-mail: lourenco@hku.hk
}

cally synthesising relatively finer materials such as clays and nano particles have been limited.

Due to their low hydraulic conductivity, clays are an essential component of capillary barrier cover systems that allow the control of infiltration. Further decreases in the hydraulic conductivity of clays have been reported when nano particles such as nano silica are introduced in them [12]. In this paper, the hydrophobicity of two clays with differing structures and that of nano silica are investigated after synthesis with an organosilane.

\section{Materials and methods}

\subsection{Clays and nano silica}

Two clays were used in this study: kaolin and halloysite. Both clays were purchased in powdered form from American Elements, California, USA and consist predominantly of aluminium oxide and silicon oxide. The particle size of kaolin $\left(\mathrm{Al}_{2} \mathrm{Si}_{2} \mathrm{O}_{5}(\mathrm{OH})_{4}\right)$ as reported by the supplier was $2 \pm 1.5 \mu \mathrm{m}$ and that of halloysite $\left(\mathrm{Al}_{2} \mathrm{Si}_{2} \mathrm{O}_{5}(\mathrm{OH})_{4} \cdot 2 \mathrm{H}_{2} \mathrm{O}\right)$ was reported as $<100 \mathrm{~nm}$ in diameter and of length 0.5 $1.2 \mu \mathrm{m}$. The nano silica particles $\left(99 \% \mathrm{SiO}_{2}\right)$, bought from HeFei XiangZheng Chemistry Technology Co., LTD, China were of mean size $17 \mathrm{~nm}$.

\subsection{Hydrophobisation reaction}

To $5 \mathrm{~g}$ samples of the clays and $1 \mathrm{~g}$ samples of the nano silica particles, were added incremental amounts of dimethyldichlorosilane (DMDCS, molecular weight of $129.06 \&$ density $1.06 \mathrm{gcm}^{-3}$ from Acros Organics, New Jersey, USA) drop by drop from a single channel pipette (Pipetman P100 from Gilson ${ }^{\circledR}$, Villiers-le-Bel, France) 

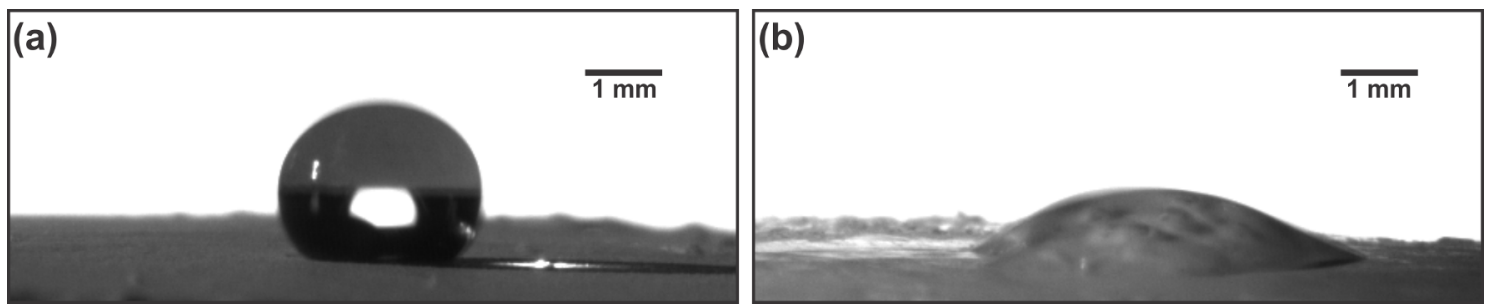

Figure 1. Profiles of $10-\mu \mathrm{L}$ drops of deionised water on (a) kaolin and (b) halloysite before hydrophobisation.

with constant and gentle stirring. The samples were then left in the fume hood for half an hour and kept in Ziploc bags for 24 hours prior to any measurements.

\subsection{Hydrophobicity assessment}

A goniometer (Drop Shape Analyser 25 from KRÜSS GmbH, Hamburg, Germany) was used to measure the CA via the sessile drop method. The sessile drop method makes a direct measurement of the CA at the three-phase point and thus quantifies the extent to which a surface is hydrophobic [13]. The sample preparation technique involved sprinkling the clays and nano silica particles over a microscope slide to which a double-sided adhesive tape had initially been attached. A 1-N weight was then applied on the resulting material so as to obtain a quasi-plain surface. This technique is similar to the sample preparation performed by Bachmann et al. [14] on coarse grained particles such as sands. A $10-\mu \mathrm{L}$ drop of deionised water was then dispensed on the samples by an automated syringe and its motion recorded by a charged-coupled device camera. The initial frame recorded after placing the drop and ending of mechanical perturbances (corresponding to an average time of $50 \mathrm{~ms}$ ) was selected. The CA was then evaluated using an image processing technique [15]. Ten CA measurements were made on each sample from which the mean value and standard deviation were calculated. The tests were carried out at a temperature of $24^{\circ} \mathrm{C}$ and relative humidity of $60 \pm 5^{\circ}$.

\subsection{Scanning electron microscope-energy dispersive spectroscopy}

A scanning electron microscope (SEM, Sigma HD FEGASEM from Carl Zeiss AG, Jena, Germany) was used for the qualitative inspections of the microscopic and nanoscopic surfaces of the clays and nano silica. The samples were first dispersed in ethanol and then sputtered with a thin layer (thickness $\approx 5 \mathrm{~nm}$ ) of a Gold-Palladium alloy in the ratio of 3:2 using a sputter coater. Images were acquired at working distances of 5-10 $\mathrm{mm}$ and at an acceleration voltage of $15 \mathrm{kV}$. The SEM, equipped with an energy dispersive spectrometer (EDS) was used to obtain semi-quantitative data on the elemental constituents of the materials before and after hydrophobisation. Three measurements were carried out on each sample of the clays and nano silica investigated for qualitative and semiquantitative analyses.

\section{Results and discussion}

\subsection{Hydrophobicity and DMDCS concentration}

The CAs of the two clays before hydrophobisation differed significantly: halloysite was hydrophilic with a CA of $23 \pm 4^{\circ}$ whereas kaolin with a CA exceeding the $90^{\circ}$ threshold $\left(93 \pm 5^{\circ}\right)$ was hydrophobic (figure 1$)$. The CA of kaolin recorded in this study is relatively larger than those previously reported in the literature, which usually do not exceed $45^{\circ}[16,17]$. This is probably due to the adsorption of water molecules on the high surface energy of kaolin which leads to a decrease in surface energy and therefore increases CA. This observation is absent with halloysite because of the water molecules in its chemical composition. Due to these water molecules and the adsorbed water molecules, the intrinsic properties of the mineral surfaces in halloysite are less relevant in dictating the CA as opposed to the cohesion of the water molecules [18]. The nano silica was initially hydrophilic with a CA of $31 \pm 4^{\circ}$.

Adding DMDCS improved the hydrophobicity of the clays and nano silica significantly, the CA increasing for all three materials when concentration increased (figure 2). The standard deviations of the CAs were at most $\pm 7^{\circ}$ and in line with previous studies carried out such as Bachmann et al. [19]. The lowest concentration used in this study, $0.25 \%$ yielded CAs close to the materials prior to hydrophobisation: $26 \pm 5^{\circ}, 103 \pm 5^{\circ}$ and $39 \pm 5^{\circ}$ for halloysite, kaolin and nano silica respectively. The hydrophobicity of these materials gradually increased as the concentration raised to $20 \%$. The CAs recorded at this concentration for the halloysite, kaolin and nano silica were respectively: $116 \pm 5^{\circ}, 143 \pm 3^{\circ}$ and $144 \pm 6^{\circ}$. The difference in CAs between the kaolin and halloysite $\left(\approx 27^{\circ}\right.$ when hydrophobised at $20 \%$ ) is attributed primarily to the differences in their structures. As shown in figure 3, kaolin consists of hexagonal platy crystals in a $2 \mathrm{D}$ structure while halloysite comprises of cylindrical nanotubes resulting in a tubular topology. With regards to their compositions, both clays are similar except that halloysite contain water molecules which may have also influenced hydrophobisation.

As opposed to studies such as Subedi et al. [10] and $\mathrm{Ng}$ and Lourenço. [20] who investigated the hydrophobisation of sand-sized particles, the hydrophobisation of the clays and nano silica as carried out here showed no plateauing despite the comparatively high concentrations. For comparison, a concentration of approximately $0.005 \%$ was shown to be sufficient to achieve maximum hydrophobicity with a clean quartzitic sand in $\mathrm{Ng}$ and Lourenço. 
[20]. However, hydrophobisation of kaolin and nano silica as carried out in this study yielded larger CAs compared to the studies performed on sand particles, where the maximum CAs were in the range of $120^{\circ}-125^{\circ}$.

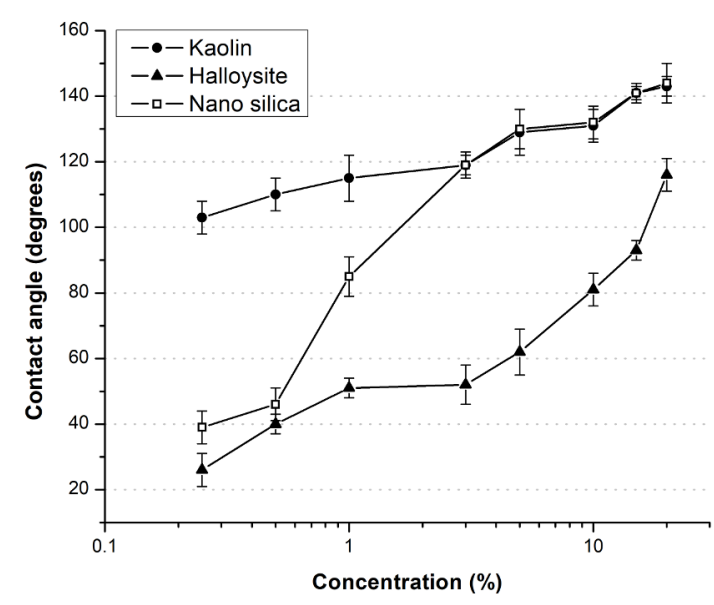

Figure 2. Variation of contact angles with increase in concentration $(\%)$ for the clays and nano silica.
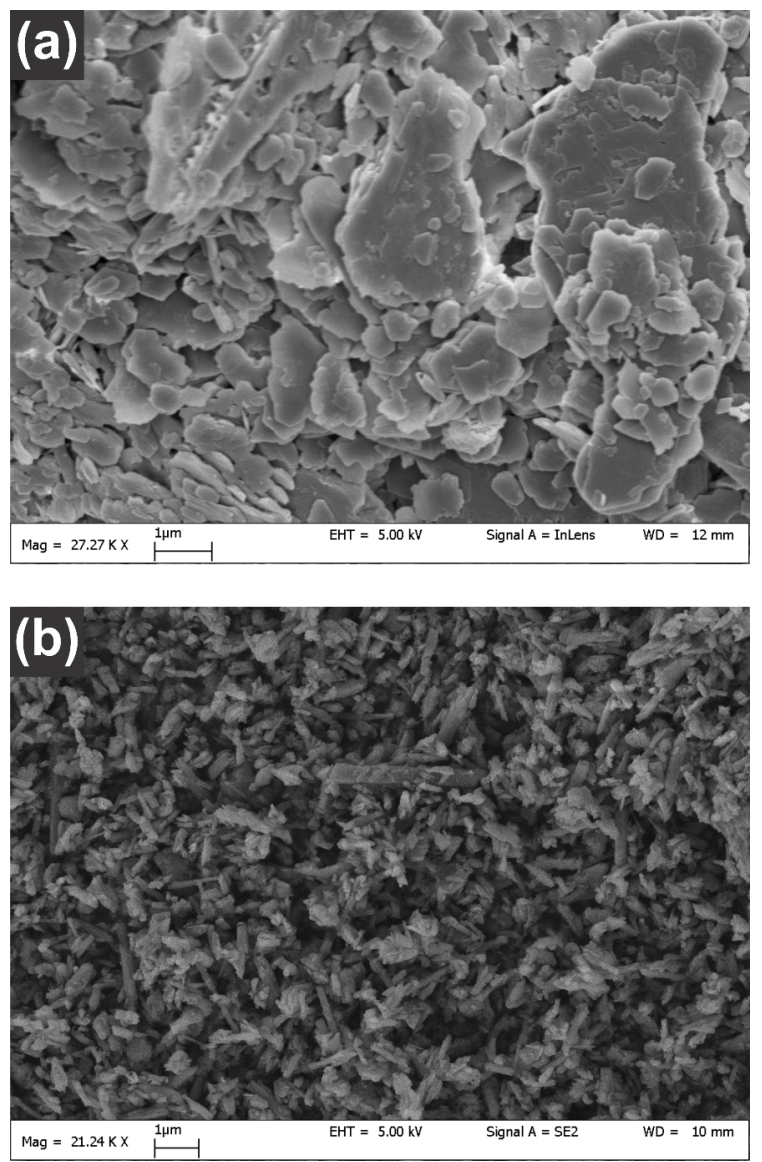

Figure 3. SEM microphotographs of (a) kaolin and (b) halloysite.

\subsection{SEM-EDS analysis of clays and nano silica before and after hydrophobisation}

A total of three areas on samples of the clays and nano silica hydrophobised at $0.25 \%, 10 \%$ and $20 \%$ were qualitatively investigated by SEM and the elemental constituents of the samples hydrophobised at $20 \%$ compared to the samples before hydrophobisation for a semi-quantitative analysis. Visual inspections by the SEM microphotographs showed no clear difference between the samples before and after hydrophobisation. Tables 1 and 2 illustrate the elemental constituents (measured with totals normalised to $100 \%$ ) of the samples before hydrophobisation compared to the samples hydrophobised at $20 \%$.

Although DMDCS consists of organic compounds, an increase in carbon content was not detected with all samples following the hydrophobisation reactions. While halloysite and nano silica had their carbon content rise up to $14.6 \%$ and $24.2 \%$, there was no change observed with kaolin. Another contradicting result obtained with the SEM-EDS analysis was the absence of $\mathrm{Al}$ in the halloysite hydrophobised at 20\%. Possible justifications for these observations include the inhomogeneity of the samples after hydrophobisation, the thickness of the resulting coatings following reactions with DMDCS, causing the X-rays analysed to emanate from within the samples and not from their surfaces and the fact that the samples investigated are not flat.

Table 1. Elemental constituents of particles (\%) obtained from SEM-EDS analysis before hydrophobisation.

\begin{tabular}{llll}
\hline Element & Kaolin & Halloysite & Nano silica \\
\hline $\mathrm{O}$ & 62.7 & 60.3 & 68.7 \\
$\mathrm{Al}$ & 13.5 & 7.4 & 0.0 \\
$\mathrm{Si}$ & 21.0 & 31.8 & 25.0 \\
$\mathrm{C}$ & 0.0 & 0.0 & 4.5 \\
\hline
\end{tabular}

Table 2. Elemental constituents of particles (\%) obtained from SEM-EDS analysis after hydrophobisation at $20 \%$.

\begin{tabular}{llll}
\hline Element & Kaolin & Halloysite & Nano silica \\
\hline $\mathrm{O}$ & 60.3 & 22.3 & 56.1 \\
$\mathrm{Al}$ & 7.4 & 0.0 & 18.3 \\
$\mathrm{Si}$ & 31.8 & 62.6 & 1.3 \\
$\mathrm{C}$ & 0.0 & 14.6 & 24.2 \\
\hline
\end{tabular}

\section{Conclusions}

This study has shown that by making use of an organosilane such as DMDCS, nano silica and clays can be rendered hydrophobic. Compared to sands, the concentration required to induce hydrophobicity in these materials is significantly larger. The maximum CAs achieved at a concentration of $20 \%$ were $116 \pm 5^{\circ}, 143 \pm 3^{\circ}$ and $144 \pm 6^{\circ}$ for the halloysite, kaolin and nano silica respectively. An increase in carbon content was observed only with halloysite and nano silica following hydrophobisation.

Because fine soils such as clays have been conventionally used as a means to restrict infiltration of water 
in e.g. landfill cover systems, rendering them hydrophobic can prolong their effectiveness over longer periods of time. However, by chemically inducing hydrophobicity in nano and micro particles as carried out in this study, their macroscopic response (e.g. water retention, permeability and compressibility) will change and needs to be explored for a comprehensive understanding of their engineering behaviour.

\section{Acknowledgements}

This work was supported by the General Research Fund (Grant 17203417) from the Research Grants Council of Hong Kong Special Administrative Region, China.

\section{References}

1. M.I. Keatts, J.L. Daniels, W.G. Langley, M.A. Pando, V.O. Ogunro, J. Geotech. Geoenviron. Eng. 144, 04018030 (2018)

2. Y. Saulick, S.D.N. Lourenço, B.A. Baudet, Geotechnique (to be published)

3. Y. Choi, H. Choo, T.S Yun, C. Lee, W. Lee, Materials 9, 978 (2016)

4. F.J. Roberts, B.A. Carbon, Soil Res. 10, 35 (1972)

5. K.Y. Chan, Soil Sci. Soc. Am. J. 56, 326 (1992)

6. C.M.M. Franco, M.E. Tate, J.M. Oades, Soil Res. 33, 253 (1995)

7. P.D. Hallett, I.M. Young, Eur. J. Soil Sci. 50, 35 (1999)
8. A. Ellies, C. Ramirez, R. Mac Donald, Catena 59, 69 (2005)

9. D.A.L. Leelamanie, J. Karube, Soil Sci. Plant Nutr. 55, 457 (2009)

10. S. Subedi, K. Kawamoto, L. Jayarathna, M. Vithanage, P. Moldrup, L.W. de Jonge, T. Komatsu, Vadose Zone J. 11, (2012)

11. J.-P. Bardet, M. Jesmani, N. Jabbari, Geotechnique 64, 341 (2014)

12. M.R. Noll, C. Bartlett, T. Dochat, Proceedings of the 6th National Outdoor Action Conference on Aquifer Restoration, Ground Water Monitoring, and Geophysical Methods (National Ground Water Association, Las Vegas, 1992)

13. A.W. Adamson, Physical chemistry of surfaces (John Wiley \& Sons, New York, 1990)

14. J. Bachmann, A. Ellies, K.H. Hartge, J. Hydrol. 231, $66(2000)$

15. Y. Saulick, S.D.N. Lourenço, B.A. Baudet, Soil Sci. Soc. Am. J. 81, 241 (2017)

16. J. Shang, M. Flury, J.B. Harsh, R.L. Zollars, J. Colloid Interface Sci. 328, 299 (2008)

17. W. Wu, Clays Clay Miner. 49, 446 (2001)

18. E.A. Vogler, Adv. Colloid Interface Sci. 74, 69 (1998)

19. J. Bachmann, S.K. Woche, M.O. Goebel, M.B. Kirkham, R. Horton, Water Resour. Res. 39, (2003)

20. S.H.Y. Ng, S.D.N. Lourenço, Geotechnique 66, 441 (2016) 